fact that the theory of the local production of protective substances ${ }^{6}$ suggested a procedure which successfully arrested the spread of a tubercular process after all other methods had failed. This result was obtained in the case of an ulcer which, though it had completely healed in the middle, was spreading outward in the form of a ring of indurated tissue. Its arrest and definite cure was achieved when, executing a strategic move, $I$ inoculated in a series of different positions disposed eircle-wise around the extending ring.

ACQUAINTANCE WITH TIIE PHYSIOLOGY OF TIIE IMLMUN-

IZING RESPONSE NOT A SUFFICIENT EQUIPMISNT FOR AN IMLMUNIZATOR.

Up to this point we have been dealing with the physiology of immunization and the nature of the immunizing response. For the successful treatment of bacterial disease by methods of immunization something more is required. W'e must realize the conditions under which bacteria cultivate themselves in the organism. We must understand under what circumstances bacterial products, or bacteria, as the case may be, are conveyed into the blood stream from local foci of infection. We must appreciate how the organism reacts to such autoinoculations; and we must understand how to bring the leucocytes and bacteriotropic substances which are the instruments of immunization into operation on bacteria which are cultivating themselves inside the organism but outside the blood stream.

( To be continued.)

\section{THE MANAGEMENT OF DISLOCATION AT THE SHOULDER JOINT COMPLICATED BY FRACTURE OF THE NECK OF THE HUMERUS.*}

\section{HUBERT ASHLEY ROYSTER, A.B., M.D. RALEIGH, N. C.}

The occurrence of four cases of the above injury in my own work within seven months suggested a study of the condition and will serve as the reason for choosing this subject. Even from so limited an experience one is prepared to say at the outset that fracture-dislocation at the shoulder happens more frequently than is usually supposed; that its recognition is not always an easy matter, and that its proper treatment is little understood. There are several causes for this state of affairs. Chief among these is the fact that text-books on surgery do not consider the matter in detail and teachers of surgery do not lay stress on it.

In a list of ten authors consulted, one does not mention the subject, seven deal with it in a short paragraph, while only two treat it with anything like adequate importance. Practitioners must, therefore, find difficulty and uncertainty in approaching such cases. Moreover, much carelessness is manifested in examining shoulderjoint injuries, the physician often being content with superficial manipulations and the application of a sling or a bandage. It must be admitted that a simple disloca-

6. In this connection I would throw out as a suggestion that the production of protective substances at the site of inoculation would be definitely set at rest if after the inoculation of a bacterial vaccine into a limb it were shown that an increase of protective substances in the blood could be achieved by either massage and the application of a Bier's bandage.

* Read in the Section on Surgery and Anatomy of the American Medical Association, at the Fifty-eighth Annual Session, held at Atlantic City, June, 1907 . tion of the shoulder-joint is readily seen and remedied, but when displacement is associated with fracture of the humeral neck the diagnosis and management are questions not easily determined. For the purpose of this paper its title has been made to include fracturc: both of the anatomic and surgical neck of the humerus. and these will be discussed together.

The four cases occurring in my own practice are as follows:

CASE 1. Old Unreduccd Dislocation, with Fracture of the Surgical Neck, United in Abnormal Position. History.Mrs. L. H. M., aged 52, was first seen Jan. 5, 1905. About nine weeks previously (Oct. 20,1904)) she was thrown from a carriage, striking on her left shoulder. A physician saw her soon after and recognized the nature of the injury, but failing in an attempt to reduce the dislocation, be directed his attention to the fractured humerus in order to obtain union of the bone and later to effect restoration of the joint.

Examination.-When the patient came for examination, it was seen that the left shoulder drooped, the muscles were atrophied, the arm exhibited only slight anterior and posterior movements, and the head of the humerus was immovably fixed in its new position (subcoracoid). There was apparently firm union of the fracture at the surgical neck.

Treatment.-Under anesthesia an attempt was first made to reduce the dislocation by Kocher's method. As soon as the arm was rotated outward the bone snapped and the original fracture was reproduced. An oblique incision was then made over the misplaced humeral head through the fibers of the pectoral muscles, with the intention of lifting the upper frag. ment out and restoring both the joint and the continuity of the bone. This was found to be impossible and the only re. course was to obtain a false joint at the line of fracture. The ineision was closed with drainage and the arm was placed in a sling, after bringing the shaft of the bone as nearly as possible at a right angle to the upper fragment, and as far away from it as permissible. The woman remained under treatment for about ten days and left with instructions for massage and passive motion. The result in this case has been far from satisfactory. In spite of every effort to prevent it, the fragments reunited, so that the effect of the operation is nil.. The woman can get her hand to her mouth and the arm is: of considerable service to her, but all the motions are restricted.

CASE 2. Unreduced Dislocation Showing an Undiscovered Fracture of the Anatomic Neck. History.-C. P., aged 20, while playing ball at school April 25, 1905, fell on his left shoulder. He was not seen by a physician until five hours had elapsed and during this interval his schoolmates pulled long and hard at the joint in their endeavors to "put it in place." The doctor who first attended the young man said that he reduced the dislocation and some degree of restitution was evidently obtained, for there was no pain or discomfort for a week. After that time, however, he began to suffer and applied to a neigh. boring physician for relief. It was then found that the dislocation had recurred and the patient was sent to Rex Hospital for treatment, nearly two months after the injury.

Examination.-On June 19, 1905, an examination disclosed a longstanding subcoracoid luxation of the left shoulder-joint without marked muscular atrophy; the head of the humerus seemed unusually large and irregular in shape.

Treatment.-Remembering the experience in the first in stance (Case 1), little time was lost in manipulation, but, instead, the open method was immediately resorted to. In this case a straight incision was used, going directly down ward from the acromion through the deltoid muscle to the cxtent of four inches. With the aid of forceps and fingers tue humeral head was restored to the glenoid cavity without opening the joint. Close inspection revealed a line of callus formation, and deformity, indicating a healed fracture through the anatomic neck of the humerus-the cause of failure in retaining the arm after apparent reduction. The wound was closed after inserting a small drain. A shoulder cap of plaster-of-Paris was molded to the joint and secured by roller bandages. In one week's time this was removed and passive? movement begun. The outcome of the case was most gratifying. 
Before a month had passed the boy had almost perfect use of his left arm and now (nearly two year's after) it would be hard to believe that the shoulder had ever been dislocated.

CASE 3. Old Dislocation of the Shoulder, Complicating a Comminuted Fracture of the Upper Extremity of the Hum. erus. History.--H. M. R., aged 48, locomotive engineer, stepped from his cab in the darkness, missed his footing and fell down an embankment, striking on his left shoulder. This happened June 4, 1905. He was seen at the time by a physician who told him that his injury was not serious and placed the arm in a sling. It was not until July 16, 1905, a month and a half after the accident, that the patient came, through consultation, under my care. During the interval he had received massage, electricity, hot water and passive motion. A skiagraph had also been made, which gave the impression of a fracture of the scapular neck. It was confusing rather than enlightening. Afterward it was shown that the shadow of an outlying piece of the head of the humerus had produced the conception of a broken scipula.

Examination.-On examination the region of the joint was found to be swollen so that it was impossible to make out anything definite. The movements were greatly restricted and the gentlest manipulations gave intense pain.

Treatment.-The operation of arthrotomy was performed July 19, 1905. Fy a five inch vertical incision from the acromion downward, the joint was opened through the torn capsule and there was revealed a comminuted fracture of the whole upper extremity of the humerus. Six separate fragments were found. The largest, which constituted the major portion of the articular surface, was firmly located under the coracoid process, while the rest were more or less in their proper relations to the shaft of the bone. The lines of fracture extended through and beyond the surgical neck to a distance of four inches from the upper end of the humerus. The bone tissue was soft and pulpy, while the pieces were embedded in firm adhesions. The plan pursued was to remove all the loose bone and to pack the cavity with gauze, after closing the ends of the incision, since it was out of the question to bring the upper end of the shaft into contact with the glenoid cavity. The object was to form a flail-joint and the end has justified the means. At this writing (May 14, 1907), nearly two years after the operation, the patient can use the arm for all ordinary purposes and with the assistance of the other hand can put the arm in every position except wide abduction. He says that it is much better than it was a year ago.

CASE 4. Recent Dislocation of the Shoulder Associated With Fracture of the Surgical Necli of the Humerus. History.M. P., a farmer aged 60, July 25, 1905, fell from a wagon piled ip with wood, into a ditch 12 feet below. He was picked up and given all necessary first aid.

Examination.-Four hours later, when seen in consultation, it was readily found that, besides a compound fracture of the right femur, the man had sustained a subeoracoid dislocation of the left humerus, with a fracture of its surgical neck.

Treatment.-Under anesthesia in his physician's office a fruitless attempt was first made to reduce the dislocation; the anterior incision was then made from the acromion downward. the head of the bone exposed and replaced without the slightest difficulty. No wiring or suturing of the bone ends was needed, as they came into absolute apposition. The incision was closed without drainage, a large triangular pad placed in the axilla and a plaster of Paris shoulder-cap put on. Both the immediate and remote results here were well-nigh perfect. At the present time the patient has as good use of his arm and shoulder as he ever had.

These cases have furnished valuable lessons. Their order of appearance had much to do with suggesting conclusions which are the natural outcome of this experience. It will be observed that, first, there came a case in which the patient was treated according to one of the formerly-authorized modes of procedure, viz., allowing the bones to unite in their abnormal position with a view to reducing the dislocation later, and that the final result was practically a failure. In the second, difficulty in reduction and in maintaining it was due to an overlooked fracture of the anatomic neck of the humerus, a thing which could not have escaped notice with the open treatment. In the third is shown a failure to ascertain the true condition, even with the aid of the Roentgen ray, until the joint was opened. The last instance is an example of an ideal method with an ideal result.

Concerning the issues raised in the first case, it may be recalled that before the days of anesthetics immediate attempts at reduction were rarely successful. "The older writers," says F. H. Hamilton," "almost without exception, agree in declaring the reduction of these dislocations impossible until the fracture had united. And so late as the year 1828 we have the report of a case treated in this manner by a surgeon in Massachusetts." Hamilton gocs on to observe that "in the event of a failure by these means the case ought to be treated as a fracture, and the earliest period after the union of the fragments should be seized on to accomplish the reduction of the dislocation."

But Gross, ${ }^{2}$ in 1882 , after stating the difficulties of reduction and noting the recommendation "to let the dislocated head of the bone remain in its unnatural situation," says :

Such an idea, however, it seems to me, must be perfectly delusive; for it is impossible, under such circumstances, for Nature to make a good or useful joint. Instead, therefore, of pursuing such a practice, I should not hesitate, if a case of the kind were to present itself to me, to cut down on the dislocated bone and push it back into its natural position; or if this be impracticable or deemed inexpedient, and the head of the bone be found to compress the axillary plexus of nerves, to perform excision.

It must be evident that anything is preferable to leaving the dislocation unreduced. Most of the cases so treated will come to the surgeon after they are "old," that is, when fixation has occurred, and generally there is then no alternative but excision. Old unreduced dislocations are the source of veritable nightmare to the practicing surgeon, whether he be the beginner or the master, and compared to them ununited fractures pale into nothingness.

Besides the trouble in reduction, one is liable to break the bone in the attempt, as was done in the case reported. 'This accident has happened to operators many times. T. S. K. Morton ${ }^{3}$ records two instances, happening on successive days, in which he fractured the neck of the humerus while applying the Kocher method to old dislocations of the shoulder (without previous fracture). Finckh ${ }^{4}$ also mentions two cases. In one in which the arm was dislocated three months before, the bone was broken by rotatory movements, and in the other, a month old, by forcibly raising the arm. Pseudarthrosis was obtained in both with good results. Another case is that of Zschock, ${ }^{5}$ who, in an attempt to reduce a dislocation of threc months' standing, fractured the humerus in the vicinity of the head and the patient recovered perfect use of the arm.

The second case inculcates the perplexities of diagnosis as nothing else could, emphasizing the fact that so many cases of supposedly simple dislocations at the shoulder are found, after being exposed to view, to be complicated by fracture of the neck of the humerus.

1. Fractures and Dislocations, 1866 .

2. System of Surg., vol. i. p. 982 .

3. Philadelphia Polyclinic, Dec, 15, 1894.

4. Beitr. z. Klin. Chir., 1896-7, xvil.

5. Heitr. z. Klin. Chir., 1904 ; supplement Heldelberg clinfc, 1903. 
Especially is this true of the anatomic neck. In this condition accurate diagnosis is at times impossible and, therefore, rational treatment can not be applied with confidence. A failure to observe this complication explains the predicament often encountered of a shoulder thought to be restored, because there was free movement, when in reality there was the preternatural mobility of a fracture within the joint. If this were a new matter one would feel much more as if it were necessary to go further into details.

Several important cases are reported in the literature. Engle $^{6}$ noted the existence of a former fracture at the anatomic neck in the case of a man 54 years old, who had a dislocation reduced (?) without anesthesia, but whose shoulder had never ceased to give him pain; reduction under narcosis was unsuccessful and an incision was made, revealing the condition as expressed above. Schüller ${ }^{2}$ relates the instance of a woman 81 years of age who sustained a fracture of the scapula (through the glenoid fossa), with some doubt as to whether there was also fracture of the humerus. The accident occurred Feb. 28, 1898, and not until May 1898, was a Roentgen ray picture taken, which showed a fracture of the scapula as specified, and, besides this, a healed fracture of the head of the humerus through the anatomic neck.

The same conditions may obtain in fractures of the surgical neck, though this particular injury is more readily recognized. Finck ${ }^{4}$ mentions a case in which, two years after a luxation of the humerus, the patient complained of pains running from the shoulder downward, with a loss of power in the arm and fingers and a weakening of the radial pulse on that side. After incision the arm was replaced, when there was discovered a repaired fracture of the surgical neck of the humerus, with a considerable callous thickening.

That the Roentgen ray is not always reliable is proved by the third case in our series. Interpretation of the findings is the important element, and this may present as many difficulties as the ordinary examination. Other instances are not lacking to show failures of the skiagraphic view. In a demonstration of skiagrams of fractures of the upper end of the humerus, Immelmann ${ }^{8}$ thus speaks of the question under consideration:

Diagnosis is especially difficult in the case of associated dislocation of the fractured head of the humerus, and correct diagnosis is then possible only when the case comes under immediate observation. If there is much swelling and displacement of the fragments, the configuration can not be recog. nized.

A unique case of C. B. Porter's forcibly impresses the point taken. It was a double dislocation of the humerus in which the Roentgen ray showed no evidence of fracture, but, on a failure to reduce either of the luxations under ether, incisions demonstrated fractures of the surgical neck of the humerus in each and good results followed in both.

The last case on the list was approached in the light of knowledge just gained from the first three and, occurring at such a time, gave a favorable opportunity to apply the principles already settled on as a consequence of this experience. It had been observed that the obstacles in the way of successful management of these cases were, first, the uncertainty of diagnosis; second, the practice of waiting too long before resorting to the so-called radical measures; and, third, the fact that

6. Arch. f. Klin. Chir., 1897, Iv.

7. Arch. f. Orthop., 1904, ii, 58

8. Deutsche Med. Wochschr., Mar. 12, 1903, 83

9. Boston Med. and Surg. Jour., April 2, 1903. damage was done and nothing accomplished by too severe and prolonged manipulations.

The case in question was a propitious one. The accident had happened but a few hours before, the diagnosis seemed assured and no undue handling of the parts was indulged in. The test was sufficiently rigorous, however, for the patient was the oldest in the series and had other injuries, while the operation was done in the country at the physician's office and none but the simplest means were at hand for securing aseptic technic. The outcome of the case was all that could be wished for.

The question spontaneously comes: Is it not better to cut down at once, in every case of dislocation at the shoulder-joint associated with fracture of the anatomic or surgical neck of the humerus, without subjecting the parts to the traumatism incident to the usually vain endeavors of reduction by the ordinary methods? If the evidence adduced here shall be taken as a guide, this query will be answered in the affirmative. An injury of this sort is to be looked on as an emergency needing a surgeon's immediate attention, just as an acute appendicitis or a strangulated hernia would be regarded. Indeed, the comparison might be pushed further, and it would be proper to place manipulation of the joint under these circumstances on the same footing as taxis in a case of strangulated hernia. No modern surgeon thinks it justifiable to use prolonged taxis, but opens the canal, reduces the hernia and performs a radical cure at the same time. So in fracture-dislocation of the shoulder the deduction is forced on us that quicker recoveries, better permanent results and fewer deformities will be obtained by the early incision. Even in cases of doulbt it is preferable to expose the parts to view rather than to wait in the hope that Nature and time will clear it up.

\section{REVIEW OF CASES IN THE LITERATURE.}

Though the literature of this subject is not voluminous, there may be seen many instances on record illustrating just the need for enforcing the points developed above. Schoch ${ }^{10}$ describes the case of a patient who came to him two days after injury with a temporary setting, in which bloodless reduction, in spite of every possible manipulation, proved impracticable. The patient was then kept in a recumbent position for two weeks with iced bandages applied to the shoulder. A skiagram showed a fracture at the surgical neck of the humerus with dislocation. An incision confirmed this diagnosis, and the reduction was effected with comparative easc, giving a good result after some months. It would appear that a more rational plan was to make the skiagram when the patient first came in and then cut down on the joint, not waiting for fourteen days to pass. In his report Schoch collects from previuus writers nine cases, in which arthrotomy had been performed all with more or less good effects. In the discussion of a paper by Dollinger, cation of dislocation of the shoulder and fracture of the surgical neck of the humerus the surgeon should resort to laying open the injured part by incision, followed by suture and reduction of the dislocation"-a course of treatment that he pursued successfully in one case.

McBurney, ${ }^{12}$ who has done much to develop the treatment of this condition, has reported two cases of complicated shoulder dislocation, one associated with frac-

10. Beitr. z. Irlin. Chir. 1900-1. xxix. 103

11. Centrbl. f. Chir.. Dec. 6, 1902, xlix.

12. Ann. Surg., 1896, xxiil, 501; Trans. Amer. Surg. Assn., 1903, $x \nabla, 323$. 
ture of the anatomic and the other of the surgical neck of the humerus. In the first case (1896), seen three weeks after the injury, prolonged manipulation failed, the incision was made, the fragments reduced and adjusted and sutured with catgut. At that time he stated that the "open method is not recommended except in cases where proper and harmless methods to reduce by manipulations have been faithfully tried and failed." Seven years later (1903), however, in reporting the second case, in which the patient was referred to him two weeks after the injury, no account of any preliminary manipulation is given, but the incision was made as before, and such perfect apposition was secured that no suturing was deemed necessary. Four months later the patient claimed that the arm was as good as before the injury. A comparison of these two cases will show that a sounder course is to do a prompt arthrotomy without previous manipulation and that in most instances suturing will not be required.

\section{FREQUENCY.}

A few estimates have been made on the frequency of the injury under consideration. Jones ${ }^{13}$ states that out of two hundred complicated dislocations of the shoulder skiagraphed he found sixteen connected with fracture of the surgical neck of the humerus. In all the cases the patients were over 30 years, most commonly between the ages of 40 and 50 . Dollinger ${ }^{11}$ collected nineteen cases of dislocated shoulder in his clinic and three were associated with fracture of the upper extremity of the humerus. Finckh places the highest rate of plain shoulder dislocations between the ages of 21 and 30 years, while he reports five cases in which there was also fracture of the humeral neck and the ages of these ranged from 49 to 64 years. Apparently, then, the condition occurs more often than many may imagine, and is seen later in life than cases of simple luxation of the shoulder.

\section{METHODS OF REDUCTION.}

In regard to methods of reduction, it may be said that there are no specific directions to be given. The difficulties attending replacement, particularly in "old" cases, have been demonstrated and are vividly realized by one who has tried it. There is nothing more unruly than the misplaced head of a bone when its connection with the shaft has been severed. Suggestions, however, are now and then offered which may be of service. Jones ${ }^{13}$ thinks that the dislocation should be reduced at the earliest moment. A method which has proved most successful in his experience is the forcible extension of the arm held vertically, with often very hard pushing upward of the fragment. He very rightly asserts that, having reduced the dislocation, the fracture is of comparatively little moment. Within two years Hamilton had two cases in which he could not effect reduction, though he had the patients under ether (one for over an hour), with the result that the fractures united in both cases promptly, and attempts were subsequently made to reduce the dislocation, but "to no purpose." He states further that "it is quite doubtful whether extension in these cases is of any service."

No one will deny that the average practitioner of medicine, or, indeed, the experienced surgeon, can not easily reduce such a dislocation, but that in the majority of cases he will fail.

13. Brit. Med. Jour., June 16, 1896, 1386.

\section{OPERATIVE TECIINIC.}

The technic of the open treatment presents less difficulty, granting an ordinary acquaintance with the principles of surgical procedure. The incision to be preferred, by all odds, is that beginning at or near the acromial process and passing directly downward through the fibens of the deltoid muscle or between that and the pectoralis major. Incisions in any direction over the dislocated head of the humerus are not to be advised, as there will surely be trouble in returning the bone into the glenoid cavity. In recent cases the luxation rarely fails to be reduced with facility; in longstanding ones, reduction is always troublesome and at times impossible. Special instruments are occasionally required. Different operators have employed a gimlet, cork-screw, bone forceps or other device.

McBurney was probably the first (1896) to use a specially-designed hook, which is inserted into a hole previously drilled into the bone and with which great force can be applied. In one case Curtis ${ }^{14}$ could not replace the head of the humerus by this instrument, because the bone was too soft and the hook pulled out; so that he divided the capsular bands and, by means of his finger and blunt instruments used as levers, he was finally able to force the head into the glenoid fossa. Gaudier ${ }^{15}$ speaks of effecting reduction by the aid of a Jacvël hook.

\section{DRESSINGS.}

Having replaced the head of the bone and adjusted the fragment to the shaft, the next step is the retention dressing. The ideal case seen and incised early, will hardly ever need suturing or wiring of the bone ends. The late cases will sometimes demand this. After proper apposition is obtained, some appliance must be put on both to keep the bone in line and to protect the joint. The dressing most in vogue on the continent has been the Middeldorp triangle, which is formed of three narrow wooden splints made together as a frame and having its apex in the axilla. The sole object of this apparatus is to keep the arm in a position of abduction. Such a position may be had in other ways. It can be done by applying plaster-of-Paris bandages to the chest and upper extremity so as to hold the arm abducted at an angle of 45 degrees, as used by Judet ${ }^{16}$ in three cases.

Schüller tells of obviating pressure on the thorax by an "angle-iron" bandage of sodium silicate applied, in his case, to a patient 81 years old. The arm in abduction is certainly an important element in the treatment, but one need not feel dependent on any particular form of apparatus. A wedge-shaped pad in the axilla and a shoulder cap of plaster-of-Paris put on with a roller bandage will answer every purpose. The aftertreatment may be summed up in a word by saying that under no circumstances should the fixation-dressing be kept on longer than two weeks and that, of course, massage and passive motion should be begun early.

\section{CONCLUSTONS.}

1. Fracture of the neck of the humerus, complicating dislocation at the shoulder, occurs more frequently than is usually supposed.

2. The injury is difficult of diagnosis and often escapes the most careful external observation or even the scrutiny of the skiagraph.

14. Ann. Surg., 1S96, xxiil, 737.

15. Rev. de Chir., 1904, xxx, 800 .

16. La Presse Méd., Jan. 26, 1907. 
3. Ordinary expectant methods have produced many useless arms and functionless joints.

4. The only rational treatment is to cut down over the joint, reducing the dislocation and setting the fracture at once, immediately after the injury.

\section{DISCUSSION.}

Dr. Albert Kocher, Berne, Switzerland, stated that he has seen in his country many cases of fracture of the shoulder joint combined with dislocation. He was interested to hear that Dr. Royster has seen cases in which the fracture went through the anatomic neck of the humerus, as he has only observed cases where the surgical neck of the bone was fractured combined with dislocation of the shoulder joint. As to the etiology of the fracture, he thinks that there must be an injury, especially to the joint, to cause a dislocation and fracture combined of the shoulder and the bone itself. That is the experience he has. had in these cases. Dr. Kocher regretted that cases are seen in which the fracture is produced by attempts at reduction of the dislocation; that is to say, when the method of reducing the dislocation advocated by his father, Prof. T. Kocher, has been tried. His present opinion is that an exact diagnosis should be made in dislocation of the shoulder joint as to the place of the dislocation so as to make a good reposition. The method is not to be applied to every dislocation of the shoulder. The use of the method in a case where it is not applicable, is followed, not infrequently, by a fracture of the surgical neck of the humerus. Dr. Kocher agreed with the essayist as to the treatment. The diagnosis is to be made at once, and operation should follow the diagnosis. The Koch. ers cut down in front of the bone without going through the deltoid muscle, but between the deltoid and pectoral muscles, so as to prevent any muscle injury.

\section{I)YSENTERIC ABSCESS OF THE LIVER IN THE PHILIPPINE ISLANDS.* JOHN R. MCDILL, M.D. MANILA, P. I.}

As a complication of intestinal amebiasis, hepatic abscess is the most distinct surgical disease of the tropics. It occurs usually in neglected, ulcerative dysenteries of young male adult Americans or Europeans, although amebic dysentery is very common and runs a milder course among Filipinos, Japanese and Eurasians. The Chinese are rarely found in our hospitals, and it is believed that their habit of tea drinking and eating cooked foods protects them, to a great extent, from tropical bowel diseases. Liver abscess is occasionally found in all these races, but the whites furnish over 90 per cent. of the cases.

Since American occupation, dysentery, its cause and its curability have become so generally understood, even among the laity, that often on the first appearance of bowel trouble a specimen of the stool is sent for examination, and when amebas are found patients submit to rational treatment until cured; and, as examination of the stools is routine practice in cases of all kinds, amebic disease is now recognized early. The result is that abscess of the liver is already becoming more infrequent.

Alcoholic excesses are almost always a prominent part of the clinical history. The relative infrequency of liver abscess among the exceedingly temperate natives, who are also sparely provided with fatty tissue, even in the liver, which is normally a most important storehouse of fat, points to overindulgence in drink and food as an important predisposing cause. A liver damaged by

* Read in the Section on Surgery and Anatomy of the American Medical Association, at the Fifty-eighth Annual Session, held at Atlantic City, June, 1907. alcohol in a man with amebic dysentery, as in typhoid and other enteric diseases, is the constant receptacle, through the portal circulation, of quantities of septic matter, intestinal parasites and micro-organisms, acting as a septic vault and filter for the diseased intestine.

That large amounts of such materials are disposed of by even the best of livers without abscess formation is one of the most remarkable characteristics of this organ; its inherent ability in this respect is no doubt aided by its most important anatomic feature of having two systems of blood supply.

When the intestinal disease is very active and ulcerating, there often occurs an acute parenchymatous, cloudy swelling of the entire liver, creating the general locus minoris resistentia. A septic ameba-laden $\mathrm{em}$ bolus from the ulcerated colon, of sufficient size to block a portal capillary in such a liver, is probably the only real beginning of an abscess. Wonder is that abscesses are not more frequent. Amebas and their symbiotic and other bacteria reach the liver through the portal blood stream more or less constantly during an intestinal amebiasis. Musgrave and (leggi began publishing in 1904 a work which plainly established that amebas are amenable to changes of environment and that the power of an ameba to propagate under new conditions depends on the similarity between its new environment and its former one and also possibly on its ability to produce lesions in the tissue. They have shown this to be true of intestinal infections, and might not the occurrence of liver abscess depend, as they point out, not so much on whether amebas reach the liver, but on whether the liver environment had been brought to a condition approaching that of the ameba infectrt bowel.

Musgrave is continuing his government laboratory experiments, also his clinical observations in St. Paul's Hospital, Manila, and the importance of the possibility of an explanation of the exact mode of action of amebas in producing pathologic lesions can not be overestimated.

The development of an abscess may be exceedingly slow in some cases, and Musgrave has established the fact that an amebic abscess of the liver may exist without discoverable lesions in the bowel at the time of the death of the patient. In some of such cases there was a clear history of dysentery months before; in one case no history could be elicited, but Musgrave's conclusion is justifiable, that all cases in which, at autopsy, intestinal lesions were not discernible, the patient had previously had amebic colitis from which amebas reached the liver during the period of bowel ulceration. Cases of abscess apparently occurring years after a dysentery are probably of an unnoticed and recent attack; diarrhea is not a constant symptom of amebic dysentery. Such cases have also been explained by some as an aroused latency or secondary infection of an old encapsulated and partly resorbed small abscess.

\section{LOCATION, SIZE AND NUMBER.}

Abscesses of the liver vary in size and number from the solitary one, in over 60 per cent. of the cases, which may even occupy the entire right lobe, to the multiple, disseminated ones occurring in tens or hundreds and varying in size from a pinhead upward. The cases coming to operation have usually been either single or at most two or three in number which coalesced by in-

1. Publications, Blological Laboratory Bureau of Science, Manila, P. I., 1904, xviil, 1. 